\title{
БИТУМНЫЕ ПОКРЫТИЯ ДЛЯ ЗАЩИТЫ АРМАТУРЫ ОТ КОРРОЗИИ В СЛАНЦЕЗОЛЬНЫХ БЕТОНАХ
}

\author{
н. дИЛАКТОРСКиИ,
}

доктор геолого-минералогических наук

\section{л. оит}

\section{А. БЕЛЬЧЕНКО}

Вопрос сохранности арматуры в сланцезольных бетонах для нашей республики, в особенности в связи с пуском новых заводов сланцезольных строительных материалов, имеет огромное значение.

Қак показали исследования [3], составы антикоррозионных покрытий арматуры, рекоменлуемых для применения в обычных бетонах $\left[{ }^{1,2}{ }^{2}\right]$, не обеспечивают защиту арматуры от коррозии в сланцезольных бетонах.

Если защитное покрытие состава

портланд-цемент -100 вес. частей
нитрит натрия $-10 \quad, \quad$,
казеин
вода

рекомендованное «Указаниями» НИИЖБ при толщине слоя не менее 0,5 мм хорошо защищает арматуру от коррозии в обычных бегонах, то для применения его в сланцезольных необходимо изменение как состава, так и толщины покрытия.

Причиной, вызывающей усиленную коррозию арматуры, являются сернокислые и хлористые соединения, присутствующие в сланцезольных бетонах [?].

Влияние ионов хлора и сульфата, возникающих в водном растворе при затворенни вяжущего, на общий процесс коррозии арматуры состоит в том, что они разрушают защитную пленку окислов $\left[\mathrm{Fe}(\mathrm{OH})_{2}\right]$ на анодных участках поверхности металла, открывая доступ кислороду воздуха к катодным участкам, тем самым способствуют протеканию электрохимического процесса коррозии с кислородной деполяризацией.

Что касается влияния нона сульфидной серы на коррозию арматуры, то оно незначнтельно, и им можно пренебречь.

Поиски и испытания эффективных средств защиты арматуры от коррозии в сланцезольных бетонах проводились нами в двух направлениях: исследование защитных средств химического действия (ингибиторов коррозии) и защитных свойств изолирующих покрытнй.

К группе защитных средств химического действия следует отнести и предварительную химическую обработку (пассивирование) поверхности арматуры.

Механизм действия ингибиторов коррозии состоит в том, что коррозионные процессы сильно замедляются или полностью приостанавливаются в результате взаимодействия химического вещества (ингибитора коррозии) с поверхностью металла. 
Из всех испытанных нами химических средств защиты арматуры от коррозии в сланцезольных бетонах - $\mathrm{NaNO}_{2}, \mathrm{~K}_{2} \mathrm{Cr}_{2} \mathrm{O}_{7}, \mathrm{~K}_{2} \mathrm{CrO}_{4}, \mathrm{Na}_{2} \mathrm{CrO}_{4}, \mathrm{BaCrO}_{4},\left(\mathrm{NH}_{4}\right)_{2} \mathrm{HPO}_{4}-$ наилучшие результаты показал нитрит натрия как в составе покрытия, так и введенный в обшую массу бетона.

Нитрит натрия, добавленный в общую массу плотного бетона в количестве $3 \%$ от веса вяжущего, полностью предохраняет арматуру от коррозии.

При введении 4\% нитрита в общую массу пенобетона после двухлетнего срока хранения в камере для ускоренных испытаний (соответствует 10-12 годам хранения в естественных условиях) заметна незначительная коррозия, которая практического влияния на работу арматуры оказать не может.

Однако введение таких количеств нитрита натрия в общую массу бетона обходится дорого, поэтому его обычно применяют в составе защитных покрытий, стонмость которых примерно в 6 раз меньше.

Нитрит натрия, введенный в состав покрытия в количестве 40 весовых частей на 100 весовых частей портланд-цемента при толщине слоя покрытия 1 мм, полностью защищает арматуру от коррозии. Вместе с тем необходимо отметить, что цементно-нитритное покрытие обладает существенными технологическими недостатками: в условиях производства оно плохо выдерживает удары и тряску при транспортировке и укладке каркасов в формы, требует особого внимания при высушивании каркасов, покрытых слоем обмазки.

Запитное действие изолирующих покрытий заключается в том, что они образуют диэлектрический слой между поверхностью арматуры и агрессивной средой и создают преграду для проникновения водных растворов электролитов и кислорода воздуха к поверхности арматуры.

В течение 1959-1961 гг, нами былн проверены защитные свойства в среде сланцезольного бетона следующих изолцрующих покрытий: лакокрасочных, высокополимерных композщий и покрытий на основе нефтяных и сланцевых битумов.

Установлено, что ни лакокрасочные, ни смоляные покрытия не способны защищать арматуру от коррозии в сланщезольных бетонах.

Хорошую защиту дают фенольные полимеры типа клеев БФ-2 и БФ-6, но после затвердевания (полимеризации) сцепление их с бетоном практически отсутствует. Исследования по улучшению сцепления покрытия с бетоном нами не проводились.

Высокое сцепление с бетоном дают пластмассовые покрытия на основе полистирола, но они недостаточно защищают арматуру от коррозни.

Сравнительно хорошую защиту арматуры от коррозии в сланцезольных бетонах дает так называемое холодное битумное покрытие (табл. 1), необходимая вязкостЕ которого достигается путем растворения нефтяного битума марки БН-V каким-либо органическим растворителем (бензином, толуолом, бензолом и др.). В качестве наполнителя обынно применяют портланд-цемент, который вводится в растворенный битум в количестве $4-6$ весовых частей на одну весовую часть сухого битума.

Существенным недостатком холодного битумного покрытия является необходимость его высушивания в течение продолжительного времени (10-15 часов в естественных условиях), в связи с чем требуются большие производственные площади, оборудование для сушки и удаления паров высыхающего растворителя.

Однако основным недостатком холодного битумного покрытия для применения его в условиях пронзводства следует считать токсичность, воспламеняемость и взрывоогасность растворителей.

Битумно-глинистые пасты (табл. 1) по своим защитным свойствам стоят ниже холодного битумного покрытия. Битумно-глинистая паста № 2 составлялась по рецептуре кандидата технических наук Соколовича В. Е. $\left[{ }^{2}\right]$. Для остальных составов применялись как нефтяные, так и сланцевые битумы различных марок.

Добавление нитритного илн хроматного ингибиторов в состав пасты, рекомендуемой Сокпловичем, несколько улучшает ее защитные свойства. При добавлении фосфатного ингибитора зашитные свойства битумно-глинистой пасты ухудшаются. 
Таблица 1

Противокоррозионные свойства битумных покрытий в сланцезольных ячеистых бетонах после полуторагодичного хранения образцов в камере для ускоренных испытаний

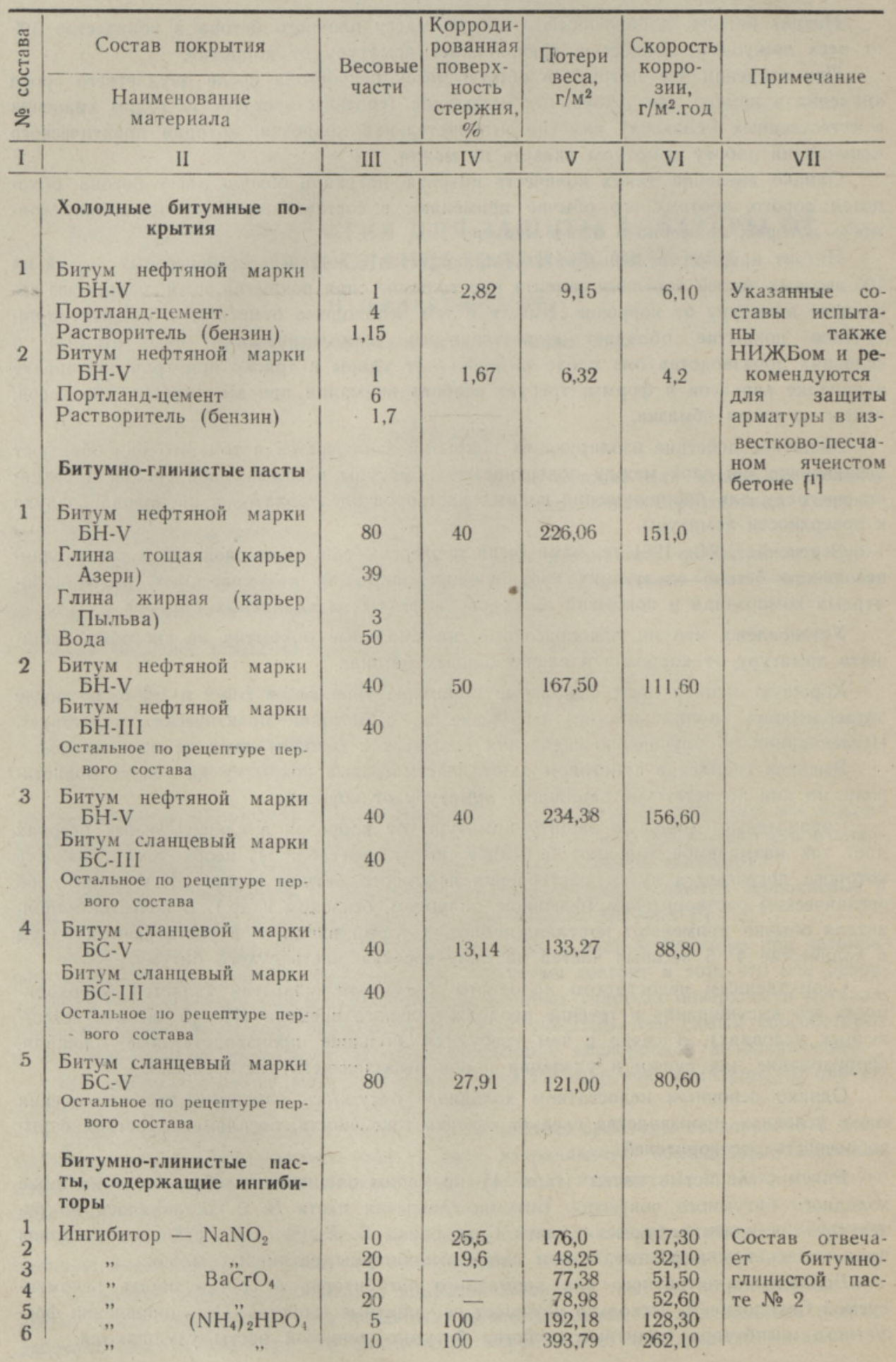


Продолжение таблицы 1

\begin{tabular}{|c|c|c|c|c|c|c|}
\hline I & II - & III & IV & V & VI & VII \\
\hline & $\begin{array}{l}\text { Битумно-известковые па- } \\
\text { сты }\end{array}$ & & & & & \\
\hline 1 & $\begin{array}{l}\text { Битум нефтяной марки } \\
\text { БН-V } \\
\text { Битум нефтяной марки } \\
\text { БН-III } \\
\text { Известь гашеная } \\
\text { Вода }\end{array}$ & $\begin{array}{l}20 \\
20 \\
18 \\
50\end{array}$ & 0,6 & 2,41 & 2,89 & $\begin{array}{l}\text { Данные приве- } \\
\text { дены для об- } \\
\text { разцов десяти- } \\
\text { месячного хра- } \\
\text { нения в камере } \\
\text { для ускорен- } \\
\text { ных испытаний }\end{array}$ \\
\hline
\end{tabular}

Щелочная битумно-известковая паста имеет лучшие защитные свойства, чем битумно-глинистые пасты.

Из всех изолирующих покрытий, испытанных намн, наилучшие результаты защи-ты арматуры от коррозии в сланцезольных бетонах показало горячее битумное покрытие. Есдा для холодного битумного покрытия необходимая вязкость смеси получается при помощи летучего растворителя, то для горячего она достигается путем. нагрева смеси битума с наполнителем до температуры $140-150^{\circ} \mathrm{C}$.

Для определения защитных свойств горячего битумного покрытия было испытано 18 различных смесей, в состав которых входили нефтяной или сланцевый битум марки V и тонкомолотый песок или портланд-цемент.

таблица 2

Противокоррозионные свойства горячих битумных покрытий после полуторагодичного хранения образцов

\begin{tabular}{|c|c|c|c|c|c|c|}
\hline \multicolumn{4}{|c|}{$\begin{array}{c}\text { Состав покрытия в весо- } \\
\text { вых частях }\end{array}$} & \multirow{3}{*}{$\begin{array}{c}\text { Корроди- } \\
\text { рованная } \\
\text { поверхность } \\
\text { стержня, } \\
\%\end{array}$} & \multirow{3}{*}{ 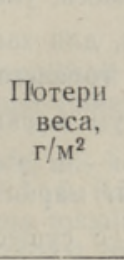 } & \multirow{3}{*}{ 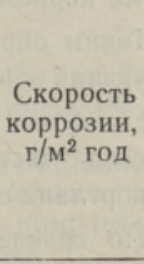 } \\
\hline \multicolumn{2}{|c|}{ Битум } & \multicolumn{2}{|c|}{ Наполнитель } & & & \\
\hline $\begin{array}{l}\text { Нефтя- } \\
\text { ной }\end{array}$ & $\begin{array}{l}\text { Сланце- } \\
\text { вый }\end{array}$ & Песок & $\begin{array}{c}\text { Порт- } \\
\text { ланд- } \\
\text { це- } \\
\text { мент }\end{array}$ & & & \\
\hline 1 & 0 & 0 & 0 & 21,49 & 39,09 & 26,06 \\
\hline 1 & 0 & 0,25 & 0 & 36,28 & 60,35 & 40,23 \\
\hline 1 & 0 & 0,50 & 0 & 38,00 & 61,67 & 41,11 \\
\hline 1 & 0 & 0,75 & 0 & 48,40 & 90,73 & 60,49 \\
\hline 1 & 0 & 1,0 & 0 & 44,00 & 82,84 & 51,23 \\
\hline 1 & 0 & 0 & 0,25 & 18,30 & 48,87 & 32,58 \\
\hline 1 & 0 & 0 & 0,50 & 10,10 . & 64,23 & 42,82 \\
\hline 1 & 0 & 0 & 0,75 & 7,66 & 33,48 & 22,32 \\
\hline 1 & 0 & 0 & 2,0 & 13,76 & 31,45 & 20,97 \\
\hline 0 & 1 & 0 & 0 & 2,05 & 14,52 & 9,70 \\
\hline 0 & 1 & 0,5 & 0 & 3,49 & 29,17 & 19,45 \\
\hline 0 & 1 & 0,75 & 0 & 3,94 & 10,97 & 7,31 \\
\hline 0 & 1 & 1 & 0 & 6,41 & 7,68 & 5,12 \\
\hline 0 & 1 & 2 & 0 & 0,88 & 1,10 & 0,73 \\
\hline 0 & 1 & 0 & 1 & 1,80 & 2,07 & 1,38 \\
\hline 0 & 1 & 0 & 2 & 0 & 0 & 0 \\
\hline $\begin{array}{l}0 \\
0\end{array}$ & 1 & 0 & 2,5 & 0 & 0 & 0 \\
\hline 0 & 1 & 0 & 3 & 0 & 0 & 0 \\
\hline
\end{tabular}

Выяснилось, что защитные свойства сланцевого битума марки V оказались более высокими, чем у нефтяного битума той же марки (табл. 2). Сланцевый битум в про. цессе гидротермальной обработки частично диффундирует в массу бетона и тем самым 
увеличивает толщину диэлектрического слоя в $3-5$ раз по сравнению с первоначальной толщиной. Нефтяной битум такого эффекта не дает. Вопрос о пригодности нефтяных битумов, обладающих другими свойствами требует дальнейших исследований.

Іортланд-цемент, как наполнитель, повышает защитные свойства битумного покрытия. С увеличением его относительного содержания коррозия уменьшается и, наконец, при соотношении веса битума к весу портланд-цемента $1: 2$ коррозия полностью прекращается. Преимущество портланд-цемента по сравнению с песком состоит в том, что он способен вступать в реакцию с водяными парами, проникающими через толщу покрытия в процессе автоклавной обработки.

С практической точки зрения к покрытию, кроме защитных свойств, предъявляются требования сцепления с арматурой и с бетоном. Сцепление горячего битумного покрытия возрастает с увеличением количества вводимого в смесь портланд-цемента. Мы установили, что для горячего битумного покрытия предельное отношение веса битума к весу наполнителя должно быть не более $1: 2,5$, так как при дальнейшем увеличении веса наполнителя смесь получается очень вязкой и погружение арматуры вызывает определеншые трудности, при этом величина сцепления арматуры с бетоном, при котором пронсходит разрушение покрытия, составляет $9-10 \mathrm{kr} / \mathrm{cm}^{2}$ (напряжение сдвига).

При указанном соотношении компонентов и температуре смеси $140-150^{\circ} \mathrm{C}$ обеспечивается вязкость, удобная для окунания арматуры в смесь. Величина вязкости находится в пределах 200-250 пуаз. Необходимая толщина покрытия $(0,8 \pm 0,2$ мм) получается однократным окунанием арматурного каркаса в ванну.

Исследования показали, что при длительном нагревании битумной смеси происхфит увеличение ее вязкости из-за постепенного роста температуры размягчения нагреваемого битума. Установлено также, что при непрерывном нагревании смеси, состоящей из сланцевого битума марки IV, имеющего начальную температуру размягчения $50-55^{\circ} \mathrm{C}$, с портланд-цементом в соотношении $1: 2$ в течение 15 суток при. температуре $140-150^{\circ} \mathrm{C}$ заметных изменений вязкости смеси не происходит. Испытания на коррозню смеси, указанного состава, также показали хорошие результаты.

Таким образом, для защиты арматуры в сланцезольных бетонах мы рекомендуем следующий состав горячего битумного покрытия:

сланцевый битум марки IV (БC-IV) с температурой размягчення $50-55^{\circ} \mathrm{C}-$ 1 весовая часть;

портланд-цемент марки «400» или «500» - 2 весовые части.

По сравнению с существующими указанное покрытие имеет ряд преимуществ, упрощающих и ускоряющих в производственных условиях операции нанесения его на поверхность арматуры:

1) покрытие не требует сушки;

2) каркасы после окунания могут заливаться бетоном через 5-6 минут, необходимых для затвердевания битума;

3) гокрытие хорошо выдерживает ударную нагрузку при транспортировке и уклідке каркасов в формы;

4) покрытие сбволакивает арматуру слоем одинаковой толщины;

5) при окунании в горячую смесь с поверхности арматуры удаляется пленка влаги;

6) в составе покрытия отсутствуют испаряюшиеся или воспламеняющиеся растворители.

\section{Выводы}

1. Полную защиту арматуры от коррозии в сланцезольных яченстых и плотных бетонах обеспечивает сланцебитумное горячее покрытие с портланд-цементным наполнителем при соотношении битума к наполнителю $1: 2$. 
2. Необходимая толщина покрытия $(0,8 \pm 0,2)$ получается при однократном окунании каркасов в ванну со смесью, имеющей температуру $140-150^{\circ} \mathrm{C}$.

3. По сравнению с существуюшими горячее битумное покрытие имеет ряд пре нмуществ.

\author{
ЛИТ Т Р А Т У Р А
}

1. Указания по защите арматуры железобетонных конструкций от коррозии, (НИИЖБ), Гос. изд. литературы по строительству н архитектуре н строительным материалам, М., 1960

2. Указание на ириготовление антикоррозионных битумноглинистых паст и способ их нанесения на арматурные каркасы, предназначенные для армирования изделнй из ячеистых бетонов. Изд. Моск, филиала Ин-та «Оргэнергострой», 1960.

3. Л. О йт, Н. Д ил акторски й, А. Бельченко, Причины коррозии арматуры в сланцезольных бетонах, Изв. АН ЭССР, сер. физ.-мат. и техн. наук, т. ХІ, № 3, 1962.
Институт строительства и строительных материалов Академии наук Эстонской ССР
Поступила в редакцию
19. IV 1962

\title{
BITUUMSED KATTED ARMATUURI KAITSEKS KORROSIOONI VASTU POLEVKIVITUHKBETOONIS
}

\author{
N. Dilaktorski,
}

geoloogia-mineraloogia doktor

\author{
L. Oit, A. Beltšenko
}

\section{Resümee}

Katsed näitasid, et nii korrosiooni vastu kui ka tehnoloogiliselt osutus parimaks $0,8 \pm 0,2$ mm paksune kuum bituumenkate, mis koosnes bituumenist (pōlevkivi mark БC-IV) ja portlandtsemendist, vahekorras $1: 2$.

Suhteliselt heade kaitseomadustega oli ka külm bituumenkate, mis koosnes bituumenist (naita mark $\mathrm{bH}-\mathrm{V}$ ) ja portlandtsemendist, vahekorras $1: 4$ või $1: 6$. Külma bituumensegu viskoossust reguleeritakse aga orgaaniliste lahustitega, mis oma toksilisuse ning tule- ja plahvatusohtlikkusega raskendavad külma bituumenkatte kasutamist tööstuses.

Bituumensavi-pastad eri variatsioonides (nii inhibiitorisisaldusega kui ka ilma) kaitsevad armatuuri korrosiooni vastu halvemini kui kuum või külm bituumenkate.

Bituumenlubi-pasta, mis on küll paremate kaitseomadustega kui bituumensavi-pastad, jääb selles osas siiski maha kuumast bituumenkattest.

Eesti NSV Teaduste Akadeentia

Ehituse ja Ehitusmaterjalide Instituut
Saabus toimetusse

19. IV 1962

\section{SCHUTZEIGENSCHAFTEN VON BITUMENDECKUNGEN AUF ARMIERUNGEN DES BRENNSTOFFASCHEN-BETONS}

\author{
N. Dilaktorski, L. Oit, A. Beltschenko
}

\section{Zusammenfassung}

Im Artikel werden Möglichkeiten betrachtet, die Armierung im Brennstoffaschen-Beton durch isolierende Bitumendeckungen gegen Rost zu schützen.

Das Versuchsmaterial bezeugt, dass von den angewandten Schutzmitteln, - sowohl hinsichtlich des Korrosionsschutzes, als auch der Technologie - die heisse $0,8 \pm 0,2 \mathrm{~mm}$ 
dicke Bitumendeckung sich besonders gut bewährte. Sie bestand aus Brennstoffbitumen (Marke EC-IV) und Portlandzement im Verhältnis von 1:2.

Relativ guten Schutz gewährleistete auch die kalte Bitumendeckung (Verhältnis 1:4 und $1: 6)$.

Die Regulierung der Viskosität der kalten Bitumenmischung erfolgt durch organische Lösemittel, deren Feuergefährlichkeit und Explosivität aber die Anwendung dieser Mischung im Betriebe erschwert.

Die Bitumen-Lehm Pasten verschiedener Zusammensetzung, mit oder ohne InhibitorenGehalt, schützen die Armierung weniger gut als es die heisse und die kalte Bitumendeckung tun.

Die Bitumen-Kalk Paste hat zwar bessere Schutzeigenschaften als die Bitumen-Lehm Pasten, ist aber schlechter als die heisse Bitumendeckung.

Institut für Bauwesen und Baumaterialien

der Akademie der Wissenschaften der Estnischen SSR
Eingegangen am 19. April 1962 